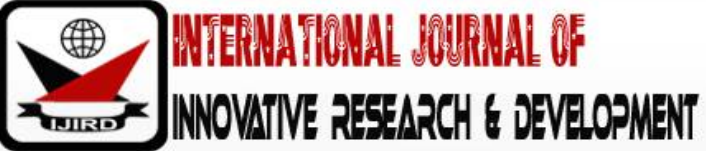

ISSN 2278 - 0211 (Online)

\section{Formalizing Ghana's Economy through an Implementation of National Identification System: Issues and Perspectives}

Dr. Ebenezer M. Ashley
Lead Consultant, Department of Finance, Banking, Economics and Business
EBEN Consultancy, Accra, Ghana
Ernest A. Lartey
Ph.D. Candidate, Department of Controller, MTA, New York City Transit, New York, USA
Bernard Obeng
Lecturer, Department of Sociology and Social Work, KNUST, Kumasi, Ghana

\begin{abstract}
:
The demand for national identification systems by economies across the globe is on the ascendency in recent years. The increasing demand could be attributed to a number of factors including internal and external insecurity emanating from terrorism threats, fraudulent activities in the financial sub-sector, challenges inherent in equitable distribution of welfare benefits to targeted beneficiaries, among others. However, availability of accurate and authentic data for effective national planning and development remains a challenge to many countries. Although some economies have made significant strides in their quest to effectively document their citizens and non-citizens resident therein to ensure efficiency in policy implementation, this remains a mirage in many other countries across the globe, including Ghana. The present study sought to examine how the adaptation and implementation of a national identification system could facilitate formalization of the Ghanaian economy to accelerate her intended development and growth in all sectors. The systematic exploratory technique, an example of the mixed methods approach to scientific inquiry, was adapted for this research. That is, the research was conducted with strong qualitative leanings though elements of both qualitative and quantitative methods were present. Secondary sources were identified as the most reliable means of gathering relevant data for the present study. These included text books, peer-reviewed articles in journals, news paper publications, and the Internet, among other sources. Findings from the study revealed adaption and implementation of national identification systems have yielded varied socio-economic results in some emerging and developing economies across the globe. Several enactments have been passed by the Parliament of Ghana and received Presidential assents to ensure the adaption and implementation of a national identification system in the country. The research outcomes revealed some socio-economic benefits to be derived from the Government's decision to adapt, install, and implement national identification system in Ghana as well as challenges that could mar the realization of those socio-economic benefits. The study recommended the need for the National Identification Authority (NIA) to adapt and implement the smart integrated system; and ensure its staffs are adequately resourced in terms of training and equipment to facilitate harmonization and integration of all public data into one data warehouse. The study further recommended the need for effective prioritization of functions of the NIA; and use of an individual's fingerprints as a unique identification in proxy for a missing or misplaced identity card. The new national identity card must be friendly to the visually-impaired; it must include a tactile feature to ease its usage by the visually-impaired. The Board and Management of the NIA must ensure value-for-money by adapting the right system for the registration process. Protection of citizens' and non-citizens' sensitive information must be of utmost concern to the NIA; sophisticated technology that could protect registrants' data against hacking should be acquired and used by the NIA. It must ensure strict adherence to and implementation of the content of the Data Protection Act of 2012, Act 843 to assure the privacy of all registrants.
\end{abstract}

Keywords: Act, biometric, national identification authority, national identification system, national identity card, national identity register, register, regulation, security theory

\section{Introduction}

The need for a national identification system to ensure issuance of national identity cards to citizens or members of society was conceived several centuries ago. Lyon (2009) affirms the resolve of Europe's modern state system to technologically identify citizens between 1400 and 1600. The surge in global population and ease in migration across various continents bring in their wake social and economic challenges such as civil and tribal conflicts, inadequate provision of infrastructural facilities, growing pressures on general public service delivery, terrorism, fraud, and crime, among others. In contemporary societies across the globe, it is becoming increasingly paramount to identify and duly categorizethe inhabitants of a country into citizens and non-citizens to help curb or prevent the foregoing socio-economic 
menace. Whitley and Hosein (2010) found unanimity among several governments across the globe to adapt and implement an identity policy to strategically stem the growing tide of global population increase on their economies.

A national identification system(NIS) refers to a technological device adapted and implemented by a government to ensure vital biographic and biometric data of citizens and non-citizens are collected and migrated into computer systems for analytical, planning and development purposes.Clarke (1994) notes the functionality of this system is to ensure the existence of a link between individual members of a given country and stream of data. National identification systems generate identity cards for citizens and other nationals as may be determined within a given jurisdiction. Michael and Michael (2006) believe an identity card facilitates our identification of persons belonging to a particular group. A national identification system enables governments to issue unique identification numbers to their citizens and other nationals. This initiative expedites government-led programs and interventions; and enables citizens to exercise their democratic franchise with relative ease. In many modern states across the globe, members of society are obliged to have an identification card, so they could call themselves citizens; and effectively participate in government-sponsored programs and schemes. Islam, Baniamin and Rajib (2012) found significant improvements in the lives of citizens of many economies across the globe today, owing to the issuance of national identity cards by the latter to the former.The findings revealed better improvements in the lifestyles of citizens with national identity cards in the near and distant future.Lyon (2009) found a positive relationship between national identity card derived from national identification system and social benefits such as improved well-being and protection against internal and external threats.

\subsection{Background of the Study}

In Ghana, the idea of issuing national identity cards to citizens was first considered and implemented in 1973. The exercise was carried out mainly in the border regions, including Brong Ahafo Region, Northern Region, Volta Region, Upper East Region, Upper West Region, and some parts of the Western Region. After three years of implementation, the registration exercise was discontinued due to financial constraints and logistical challenges. In 1987, the national identification project was revisited by the Provisional National Defence Council (PNDC) through the National Commission for Democracy (NCD). Various committees such as the Technical Implementation Committee were established to ensure continuation of the national identification project. However, actual implementation of the project suffered a setback due to financial constraints (NIA, n.d.).

A National Economic Dialogue was convened in Ghana in 2001. One of the major issues that formed an integral part of the dialogue was the need for a policy on national identification system. To ensure realization of the foregoing objective, members of stakeholder organizations were drawn together to constitute a multi-sectoral Technical Committee. The committee was responsible for studying and reviewing the 1991 report on national identification; establishing the main principles and conceptual procedures for an integrated national identification system for Ghana; identifying and recommending specific technologies for such a system; and developing plan of action and time frame for implementation of the national identification system. The Technical Committee completed its task and submitted a report to Cabinet for consideration and implementation in 2002.The report was accepted and formed the basis for Government to ensure all citizens and non-citizens legally resident in the country are covered; assist in disaster management, welfare services, healthcare service delivery, and crime prevention; enhance public services delivery to targeted groups, social security, and banking services; improve drivers' licenses and passports application processes and acquisitions; and help to increase government revenue collection and mobilization (NIA, n.d.).

\subsubsection{National Identification Authority Act of 2006, Act 707}

In 2003, Ghana's National Identification Authority (NIA) was established under the Office of the Second President of the Fourth Republic, former President John AgyekumKuffuor. The mandate of the NIA was to issue national identity cards and manage the national identification system. In 2006, the National Identification Authority Actof 2006, Act 707, was passed to give the NIA a legal backing. This Act is arranged into nineteen (19) sections. Establishment of the NIA and the movable and immovable properties, among other considerations, required for the smooth performance of its duties are stipulated in Section 1 and its related sub-sections of Act 707. Functions and objectives of the NIA including creation, maintenance, provision, and promotion of national identity cards, among others, are clearly spelt out in Section 2 and its related sub-sections. Composition of the governing body, that is, the Board, and appointment of membership to the board, among others, are outlined in Section 3 and its related sub-sections. Section 4 and its attendant sub-sections present information on the tenure of office of board members, and conditions under which a board member may resign from office or a vacancy may be deemed to have occurred. Meeting schedules of board members, how to form a quorum for a meeting, among other important considerations, are stated in Section 5 and its related sub-sections of Act 707.

The disclosure of interest and condition under which a member shall cease to be a member of the board are outlined in Section 6 and its related sub-sections. Section 7 explains modalities for the appointment of committees and the body mandated to appoint committees, that is, the board. Mode of payment and approval of allowances payable to board members of the NIA are contained in Section 8. The board's mandate to establish regional and district offices of NIA are enshrined in Section 9 and its related sub-sections.The right of the Minister responsible for the NIA to issue general directives of public interest to the board is stipulated in Section 10 of Act 707. Sections 11 through 19 of Act 707 are described as Miscellaneous Provisions. In Section 11 and its sub-sections, appointment and term of office of the Executive Secretary to the board are spelt out. The appointment is made by the President in accordance with Article 195 of the Ghanaian Constitution. Similarly, the appointment of other officers to complement the functions of the executive secretary, and the board's ability to engage in consultancy services are stated in Section 12 and its attendant sub-sections. These appointments are expected to be made by the President in tandem with Article 195 of the Ghanaian Constitution. 
Section 13 of Act 707 outlines capabilities of the President to delegate the power of appointment of public officers to work at the NIA. This is in accordance with Article 195, clause 2, of the Republican Constitution. Sources of funding for the NIA including money provided by Ghana's Parliament, funds approved by the Finance Minister, government loans, grants, and aids are stated in Section 14 and its related sub-sections. The need for the NIA to keep proper records for accounts and audit, prepare annual financial statements, and submit same to the Auditor-General for audit within 3 months at the end of each financial year, which is the same as the Government's financial year is presented in Section 15 and its related subsections. Section 16 and its attendant sub-sections state the duty of the board to present annual report and other reports of the NIA within one month after receipt of the audit report to the responsible Minister. Right of the executive secretary or any person authorized by the executive secretary to request for information that is deemed reasonably necessary for the purpose of Act 707; and the penalties thereof for non-compliance or presentation of false information are stated in Section 17 and its related sub-sections. The right of the Minister, on the advice of the board by legislative instrument, to make regulations for the NIA on mode of application for identity cards, issuance of identity cards for non-citizens resident in Ghana, and data collection method, among other regulations, are stated in Section 18 and its related sub-sections. Interpretation of key terms such as minister, data, national identity card, public agency and subvented agency used in the Act are explained in Section 19.

\subsubsection{National Identity Register Act of 2008, Act 750}

The National Identity Register Actof 2008, Act 750 was passed into law on February 15, 2008to permit the NIA to collect biometric and personal data from citizens; and to ensure protection and privacy of same. Act 750 is divided into two (2) parts (Part I and Part II), seventy-six (76) Sections, and three (3) Schedules. Part I covers forty-two (42) sections and Part II covers thirty-four (34) sections. Section 1 and its related sub-sections of Act 750 explain the types of registration including mass registration; and update of the National Identity Register. Section 2 and its attendant subsections of Act 750 state how the National Identity Register is established, maintenance of the National Identity Register as an electronic database, maintenance of the National Identity Register based on public interest, and powers of the executive secretary of the NIA to keep and maintain the National Identity Register. Section 3 and its related sub-sections outline functions of the NIA including the method through which applicants could provide their personal information to be recorded in the National Identity Register, identify secure and reliable method to verify personal information of individuals when it is in the public interest to do so; and how to deal with category of individuals exempt from registration requirements.

Section 4 and its attendant sub-sections of Act 750 explain what shall constitute the content of the National Identity Register. This includes personal information collected by the NIA in respect of citizens who are resident in Ghana and outside Ghana; and personal information of foreign nationals permanently resident in Ghana; and foreign nationals with residence permit. This section also states the personal information to be recorded in the National Identity Register in relation to a person who applies for registration. The specific types of personal information to be recorded in the National Identity Register; and conditions for recording of same are outlined in Section 5 and its related sub-sections. NIA's ability to update and rectify any error or set of errors identified in the National Identity Register; and NIA's ability to use records of the Births and Deaths Registry or any other relevant agency to complete the foregoing task is stipulated in Section 6 and its related sub-sections. Details on individuals eligible for registration are captured in Section 7 and its attendant subsections. This section states a person who is six years of age and above is eligible for registration if the person is a Ghanaian citizen resident in Ghana or outside Ghana, a foreign national permanently resident in Ghana, foreign national with a resident permit of at least twelve (12) months; and a dual citizen, that is, the person holds Ghanaian citizenship and any other citizenship. Despite sub-section (i) of Section 7, sub-section (ii) of Section7 states a foreign national who has been resident in Ghana for six consecutive years is eligible to apply to the NIA to be registered during mass registration.

Requirements for registration of a person who applies to the NIA are stated in Section 8 and its sub-sections. Some of these requirements include birth certificate; or where applicable a voter's identity card, driver's license, passport or baptismal certificate; and any other information prescribed by Act 750. An applicant who is unable to produce any of the foregoing documents shall be required by the NIA to present a relative to identify the applicant under oath; a person with a Ghanaian naturalization status shall produce the certificate of naturalization; and a person with dual citizenship shall produce relevant certificate of the other citizenship. Section 9 and its attendant sub-sections state an eligible applicant may appear in person at the appropriate registration center for collection of his or her personal information for onward recording in the National Identity Register; issuance of a collection slip by the registration officer to the applicant if the former is satisfied the latter qualifies for his or her personal information to be entered in the National Identity Register; and the NIA's adoption of other means it considers appropriate to access any individual who for practical reasons may not be able to appear in person at a registration center. Section 10 relates to persons with disability. This section affirms the need for the registration officer to ensure persons with disability who appear at the registration center for recording of personal information are offered the requisite and appropriate assistance throughout the registration process.

Powers of the NIA to verify particulars of applicants are captured in Section 11and its related sub-sections. This section allows the NIA to request for proof of particulars from an applicant, investigate, or direct a public official to investigate a matter related to particulars to be recorded in the National Identity Register; and states the methods of investigation by the NIA. The period of registration by the NIA is stipulated in Section 12. This section states the periods of mass registration shall be made known to the public by the NIA through publication in the Gazette and the mass media. Powers of the NIA, with the approval of the sector-Minister, to designate registration centers in the districts for mass registration purposes; and use of polling stations created by the Election Commission and used in the most recent general 
elections as registration centers by the NIA as far as practicable, and other considerations, are contained in Section 13 and its attendant sub-sections. Section 14 and its sub-sections explain the form registration centers should take, including their location in public buildings that are easily accessible to the general public including persons with disability. This section further states the need for the NIA to give the general public notice of location and name of a registration center prior to the commencement of registration exercise. The notice shall be provided through the Gazette, mass media, electronic and print media. Section 15and its related sub-sections of Act 750 allow the NIA to use official premises of Ghana Missions abroad as registration centers. This section allows the NIA board to direct use of other designated locations outside Ghana as registration centers. This can be done after consultation with the Minister for Foreign Affairs.

Categories of individuals eligible to access NIA registration centers are stated in Section 16 and its sub-sections. These include applicants, individuals submitting complaints or official documents to a registration officer, and persons authorized by the registration officer to enter the premises. This section states the registration officer may order an individual to leave the premises if the individual's conduct disrupts the registration process or the individual fails to explain his or her authorized presence satisfactorily. Section 17 and its attendant sub-sections explain the appointment of registration officers by the NIA. The section states for mass registration purposes, the NIA shall appoint a Chief Registration Officer. This person shall be the Executive Secretary; and appoint a Chief Registration Supervisor. Further, it shall appoint two Deputy Registration Supervisors for each district; one Regional Registration Officer for each Region; one District Registration Officer for each district; and one Chief Registration Officer and two Assistant Registration Officers for each registration center. During mass registrations, the chief registration officer reserves the right to delegate a function of that office to a registration officer or any public officer.

Section 18 and its related sub-sections spell out the duties of registration officers including exercising control over registration processes at their respective registration centers, ensuring personal information of applicants are accurately recorded, having custody of registration forms, promptly and practically recording difficulties encountered at the respective registration centers to the relevant regional or district registration officer or registration supervisor. This section also requires each registration officer to personally return each registration form in addition to registration materials in his or her custody to the executive secretary. Duties of registration assistants are enshrined in Section 19 and its related sub-sections. Some of these duties include acting as recorder of text data and biometric data clerk. Section 20 and its attendant sub-sections explain the duties of registration supervisors. During mass registration exercises, registration supervisors are expected to make frequent visits to their assigned districts; ensure the availability of essential registration materials; ensure compliance with prescribed registration processes; and promptly notify the executive secretary in writing of lapses in the discharge of duties by any registration official. Provisions for registration officials outside Ghana are made in Section 21 and its related sub-sections. In consultation with the Minister for Foreign Affairs, the NIA shall designate officers of a Ghana Mission outside the country as registration officers. Duties and responsibilities of these officers shall be the same as those stipulated in Section 18 through 20.

Section 22 and its sub-sections state a registration officer or an individual authorized by the NIA to monitor a registration exercise has the right to challenge an applicant if the applicant does not satisfy the registration requirements stated in this Act or provides false information. This section states the forms to be completed by the applicant (Schedule A), Assembly member of the implied registration center (Form B1), and chief of the hometown to which the applicant belongs (Form B2), if the applicant insists on eligibility to be registered. Powers of the NIA to constitute a District Registration Review Committee, and composition of the committee is stated in Section 23 and its attendant sub-sections. Functions to be performed by a constituted District Registration Review Committee are stipulated in Section 24 and its sub-sections. The right of an aggrieved or dissatisfied applicant to appeal against the decision of the District Registration Review Committee within fourteen (14) days of receipt of the decision is outlined in Section 25. Section 26 notes if an applicant fails to appeal against the decision of the District Registration Review Committee within twenty-one (21) days after the Committee has informed the applicant of its finding, NIA shall endorse the Committee's decision.

Section 27 and its related sub-sections of Act 750 provide for the appointment of a Chief Registration Review Officer in each region in Ghana. The Chief Justice is mandated to appoint a High Court Judge in each region as the chief registration review officer. The chief registration review officer shall determine appeals from the decisions of District Registration Review Committees in the region. An aggrieved applicant can pursue the matter to the Court of Appeal. Definition of a national identity card, powers of the NIA to determine the size of the card, its description and content; and responsibility of the holder to preserve and ensure the safety of the card are stated in Section 28 and its sub-sections of Act 750. Uses of the national identity card are stated in Section 29 and its related sub-sections. Categories of persons to whom the NIA shall issue a national identity card are outlined in Section 30 and its attendant sub-sections. Section 31 states the period of validity of a national identity card issued to the holder is ten (10) years from the issued date, subject to re-issue. Section 32 stipulates holders of national identity cards are expected to apply to the NIA for re-issue within one month before the expiration of their cards. Holders of national identity cards due for re-issue may be required by the NIA to verify accuracy of their records, and update their information contained in the national identity register. The NIA shall re-issue a national identity card to the holder when satisfied with the particulars of the holder's personal information.

Conditions for which a national identity card may be replaced by the NIA are stipulated in Section 33 and its related sub-sections. A card holder is required to notify the NIA and the police when the holder has reasonable cause to suspect the card has been damaged, stolen, destroyed or lost. This section also outlines processes to be followed by the NIA to replace the card for the holder. Section 34 and its related sub-sections outline conditions under which the NIA shall consider a national identity card invalid. The NIA reserves the right to cancel an issued national identity card if it determines the card was issued based on incomplete or inaccurate information; information recorded on the card holder in the national identity register has been modified without authorization; the card is lost, has been stolen, destroyed or 
damaged; the card has some defects; or the card requires replacement due to other tangible reasons. Conditions for which a national identity card shall be surrendered by a holder are spelt out in Section 35 and its attendant sub-sections. Section 36 and its related sub-sections state how the NIA shall acquire logistical support for various registration exercises in the country. Non-liability for acts or omissions made in good faith by members of the board and employees of the NIA is stated in Section 37.Section 38 and its sub-sections of Act 750 givethe NIA powers to require information from persons to validate the national identity register. Persons in possession of information required by the NIA for validation purposes are expected to provide same. A national identity card holder is expected to notify the NIA of any change of circumstances or error that affects his or her personal information in the National Identity Register. This information and others are stipulated in Section 39 and its related sub-sections. Acts and conducts of applicants that constitute registration offences are clearly spelt out in Section 40 and its related sub-sections. Offences relating to a national identity card are outlined in Section 41 and its related sub-sections. A person's prohibition from using an equipment orapparatus to produce a national identity card without the approval of the NIA is expressed in Section 42 and its related sub-sections. A person who contravenes this provision commits an offence and is liable to summary conviction to a term of imprisonment of not more than five (5) years.

The NIA's ability to retain, use or disclose personal information of applicants is expressed in Section 43 and its related sub-sections. This section affirms a user agency's ability to access the database of NIA; and to retain, use or disclose applicants' personal information in the performance of a function under Act 750 or any other enactment. The specific type of personal information of applicants which the NIA may retain, use or disclose is stated in Section 44 and its sub-sections. These include nationality, marital status, age, medical, criminal, employment, and education history, among others. Limits to and conditions under which the NIA can use personal information of applicants in its custody are clearly expressed in Section 45 and its sub-sections. It is the responsibility of the NIA to take reasonable steps to ensure records on personal information of card holders are accurate, complete, up-to-date, and protected. This and other related obligations are stated in Section 46 and its sub-sections. Section 47 and its attendant sub-sections affirm the responsibility of the NIA to take precautionary measures to prevent the possibility of misuse of applicants' personal information to make decisions about those applicants. The NIA shall ensure information available to third parties is protected. Section 48 and its related subsections explain conditions under which the NIA can disclose personal information of a person's entry to another person. NIA's ability to disclose personal information of an applicant to a third party without his or her consent is contained in Section 49 and its related sub-sections of Act 750.The inability of NIA, members of the board and staff of NIA to provide or disclose any personal information in relation to an applicant, entity or investigation connected to a registration or application process without lawful authority is stipulated in Section 50 and its related sub-sections. The right of an applicant to access his or her personal information under the custody of the NIA is expressed in Section 51 and its subsections. Section 52 and its attendant sub-sections explain the right of an applicant to request for correction of his or her personal information held by the NIA.

Further explanation on the right of a user agency to access, use, retain and disclose personal information of applicants in the database of the NIA is contained in Section 53 and its related sub-sections. Section 54 and its sub-sections state the obligation of a user agency to notify a person whose personal information is to be accessed in NIA's database. The purpose of the personal information and intended recipient must be disclosed to the person by the user agency. Powers of the NIA to issue guidelines on access, use, retention and disclosure of personal information by user agencies are stipulated in Section 55 and its sub-sections while Section 56 and its sub-sections state limits on use of a person's personal information by a user agency. Limits on disclosure of a person's personal information by user agencies are outlined in Section 57 and its sub-sections. Section 58 and its sub-sections reveal a user agency may only disclose personal information of an applicant if the disclosure does not invade the privacy of the person concerned. A user agency's duty to ensure the security and storage of personal information in accordance with guidelines issued by the NIA is expressed in Section 59. The right of user agencies to share personal information of applicants among themselves is stipulated in Section 60 and its sub-sections. Retention and disposal of personal information by user agencies in accordance with guidelines issued by the NIA is expressed in Section 61. An applicant who opposes NIA's decision to retain, use or disclose his or her personal may petition the Commission on Human Rights and Administrative Justice (CHRAJ) for redress. This right is stipulated in Section 62 and its related sub-sections of Act 750. Powers of CHRAJ to investigate and determine matters referred to it under section 62 are stated in Section 63 and its sub-sections. Section 64 affirms the application of provisions of CHRAJ Act of 1993 (Act 456) and CHRAJ (Complaint Procedure) Regulations of 1994 (C.I. 7) for the purposes of section 62, with the necessary modifications. Section 65 and its attendant sub-sections state it is an offence for an individual to obstruct the NIA or an individual who acts on behalf of or by the direction of the NIA in the discharge of his or her duty prescribed by the NIA. Summary conviction of individuals, including a fine of not more than five thousand penalty units or a term of imprisonment of not more than ten (10) years or both, for unauthorized access to NIA's computer resources and data are explained in Section 66 and its sub-sections. Section67 and its sub-sections state summary conviction of persons, including a fine not less than four thousand penalty units or a term of imprisonment of not less than seven (7) years or both, for unauthorized modification of the content of a computer system held by the NIA.

Section 68 and its related sub-sections state it is unlawful for a person to communicate to any other person indirectly or directly a code, number, password or other means to access personal information contained in a computer of the NIA other than the person to whom that person is duly authorized to communicate to. Summary conviction of NIA officers for unauthorized disclosure, submission or transfer of personal information from the National Identity Register is stated in Section 69. The applicable convictions in this section include a fine of not more than two thousand and five hundred penalty units or term of imprisonment of not more than five years. Other offences and their summary convictions are stipulated in Section 70 and its sub-sections. Conditions under which identity cards of holders may be accessed by law 
enforcement officers are expressed in Section 71 and its related sub-sections. The right of the NIA to collaborate with user agencies for the purpose of Act 750 is stated in Section 72.The right of the Minister, on the advice of the board by legislative instrument, to make regulations on the form to be used for the application of registration, procedures to be followed in the issuance of national identity cards, among others, is spelt out in Section 73 and its related sub-sections. Consequential amendment to Section 3 (by the insertion of sub-section (iii)) of the National Identification Authority Act of 2006, Act 707 is stated in Section 74.Interpretation of key terms such as administrative purpose, apparatus, applicant, authority, authorized person, authorized user, among others, is presented in Section 75.Transitional provisions in the issuance of valid national identity cards under Act 750 or any other enactment are explained in Section 76 and its attendant sub-sections. In the Schedule section, Form A depicts content of the registration challenge form; Form B1 indicates details of the identity confirmation form; andForm B2 shows how the NIA identity confirmation form can be completed (Refworld, 2008).

\subsubsection{National Identity Regulations of 2012, L. 2111}

The National Identity Register Regulations, L. 2111 was passed into law on February 20, 2012. This law is arranged into twenty-three (23) Regulations; and two Schedules. Regulations 1 through 3 and their sub-regulations explain the process for acquiring a national identity card, including eligibility and non-eligibility. For example, Ghanaian citizen, foreign national with permanent resident status, foreign national with cumulative residence in the country for at least 9 days, and dual citizen, among other categories. The following individuals are exempted, in spite of Regulation 1: foreign nationals working as diplomats, United Nations employees, and spouses or dependent(s) of the foregoing. Regulation 4and its attendant sub-regulations explain the process of applying for a national identity card, including collection of individual's personal information by the NIA. Particulars (data) and features of individuals expected to appear on the national identity card are spelt out in Regulation 5 and its sub-regulations. The period within which an individual is expected to collect his or her processed identity card is stated in Regulation 6 and the related sub-regulations. This regulation states the individual shall collect the processed national identity card within 120 days after the application date or within the period specified by the NIA. The NIA shall notify the individual in writing (Refworld, 2008).

Regulation 7 and its related sub-regulations of the National Identity Regulations of 2012, L. 2111 affirm mandatory use of the national identity card; and transactions that would require use of the national identity card such as applications for drivers' license and passport, purchase of insurance and personal bank accounts opening; purchase, transfer and registration of land by an individual or a related transaction that is subject to provisions of enactments; and pension transactions, among others. Conditions under which the NIA, user agency, law enforcement officer, and person authorized by law may request for the national identity card of a holder for inspection and return same to the holder are enumerated in Regulation 8 and its related sub-regulations. Powers of the NIA, user agency, law enforcement officer, and person authorized by law to verify authenticity of a national identity card are enshrined in Regulation 9 and its subregulations. The application process to replace a lost, stolen, defaced, damaged or destroyed national identity card is outlined in Regulation 10 and its attendant sub-regulations. In Regulation 11 and its related sub-regulations, the obligation of a person who finds the national identity card of another person is stipulated. The finder is under obligation to present the found national identity card of another person to the NIA or the nearest police station, among other steps (Refworld, 2008).

Conditions under which the NIA shall declare an issued national identity card as invalid, cancel it, and request the holder to surrender or return it are mentioned in Regulation 12 and its sub-regulations. Regulation 13 and its related subregulations,and personal information sharing agreement outlined in Form Three of the Scheduleoutline conditions under which data in possession of the NIA may be accessed. Conditions for which an individual could have access to his or her personal information or personal information of another individual are stated in Regulation 14 and its sub-regulations. Similarly, Regulation 15 and its related sub-regulations state conditions under which a user agency may access, use, retain or disclose personal information in the database of the NIA. Conditions under which personal information of a person shall be disclosed with or without his or her consent are captured in Regulation 16. This regulation draws on provisions in the Data Protection Act of 2012, Act 843. In Regulation 17 and its attendant sub-regulations, a user agency's limit on use, disclosure or sharing of personal information is stipulated. This regulation relies extensively on the Data Protection Act of 2012, Act 843 (Refworld, 2008).

Regulation 18 and its related sub-regulations explain conditions for which a user agency could retain, dispose of, store, and protect, that is, ensure the security of personal information. Procedures for addressing grievances are stated in Regulation 19 and its sub-regulations. Conditions under which the NIA may charge fees for services provided and payable by applicants are stipulated in Regulation 20 and its attendant sub-regulations. Using its guidelines, the NIA may specify services for which fees may be charged. The NIA is obliged to display, conspicuously, list of fees payable for its services. Conditions for which the NIA would issue national identity cards to Ghanaians living outside the country and allow for online application are explained in Regulation 21. Interpretation of key terms such as authority, board, dependent, law enforcement officer, minister, and portable identity card reader is presented in Regulation 22 and its sub-regulations. Revocation of legislative enactments under the Identity Cards Act of 1972 (NRCD 129) and enforced immediately before the commencement of these regulations is outlined in Regulation 23. In the Schedule section, Form Two shows statement to be presented by an applicant for the issuance of a national identity card while Form Three depicts how personal information sharing agreement form could be completed (Refworld, 2008). 


\subsubsection{National Identity Register (Amendment) Act of 2017, Act 950}

To ensure further provisions are made for conditions of and requirements for registration for national identity cards, mode of application for same, and requisite information to be provided by persons to whom national identity cards would be issued, among other important considerations, it was necessary for the Parliament of Ghana to amend the National Identity Register Act of 2008, Act 750. Amendments to Act 750 paved way for the National Identity Register (Amendment) Act of 2017, Act 950. This law received Presidential assent on December 4, 2017. It amends some key Sections and sub-sections in Act 750, including Sections 4, 7, 8, 22, and 27. Section 4, sub-section 2, paragraph (a) of Act 750 is amended to include thirty-one (31) different details of the applicant. Some of these include full name, sex, date of birth, place and country of birth, nationality, electronic mail address, street name, digital address code, languages spoken, occupation, color of eyes, and type of verification document, among other details.

In Section 7, sub-section 1, the phrase, "age zero,"in the opening paragraph is replaced with "of the age of six years."In sub-section 4, paragraph (c), sub-paragraph (i), the sentence, "international obligations of the republic in accordance with article 75 of the Constitution," is inserted after the phrase, "any other enactment, or." Section 8, subsection 1 is substituted for as follows: "(1) The Authority shall require an individual who applies for an entry to be made in the Register to submit any of the following identity documents: (a) a birth certificate; (b) a valid passport; (c) a valid residence permit; (d) a valid certificate of acquired citizenship; and (e) any other information as may be required by the Authority." Similarly, sub-section 2 of Section 8 is substituted for as follows: "(2) Where an applicant is unable to submit any of the documents specified under subsection (1), the Authority shall require (a) a relative of the applicant to identify the applicant under oath; or (b) two persons determined by the Board to identify the applicant under oath, where the applicant has no known relatives."Sub-section 1 of Section 22 (Act 750) is substituted for in Act 950 as follows: "(1) A registration officer or any other person may challenge an applicant if that applicant provides false information or does not satisfy the registration requirements provided for in this Act." In Section 22, sub-section 2, paragraph (b), the following insertion is made at the beginning: "member of the Unit Committee or." In sub-section 5 of Section 27, the phrase, "Court of Appeal," is substituted for "High Court."

\subsection{Problem Statement}

The demand for national identification systems by economies across the globe is on the ascendency in recent years. The increasing demand could be attributed to a number of factors including internal and external insecurity emanating from terrorism threats, fraudulent activities in the financial sub-sector, challenges inherent in equitable distribution of welfare benefits to targeted beneficiaries, among others (Lyon, 2009; Khan, 2018; Zoleta, 2018). However, availability of accurate and authentic data for effective national planning and development remains a challenge to many countries. Although some economies have made significant strides in their quest to effectively document their citizens and non-citizens resident therein to ensure efficiency in policy implementation, this remains a mirage in many other countries across the globe, including Ghana.

According to the World Bank Group (2017), an estimated 1.1 billion people in the world are not able to prove their identity. This translates into about $14.25 \%$ of the world's population which is currently estimated at 7.72 billion (World Population Review, 2019). Most of the affected people are found in Asia and Africa; and more than one-third of the affected persons are under age 18. Thesefindings affirm the significance of the United Nations' Sustainable Development Goal (SDG) on ensuring national identity for all persons by 2030. The foregoing affects governments' effective delivery of social services to targeted beneficiaries and citizens in general. Davies, Hosein and Whitley (2005) estimated the average cost of implementing the national identification system in the United Kingdom over a ten-year period at $£ 14.9$ billion (between $£ 10.6$ billion and $£ 19.2$ billion). This excluded costs to be incurred in the integration of public and private sector data; and costs to be incurred in purchasing new and sophisticated equipment for data storage and updates, establishing new facilities, and training staff to assure efficient service delivery.

The general management problem is the inability of some governments in the global economy to identify, develop and implement identification systems that would curb, significantly, security breaches and threats; improve on national development planning; and ensure equitable distribution of welfare benefits and other social services to targeted recipients. Hornung and Robnagel (2010) note in contemporary periods, the establishment of individual identity through the use of sophisticated technology has become necessary to assist governments in their socio-economic development initiatives. Though evidence of the phenomenon exists, there are no studies to clearly establish the role of a national identification system in the formalization of the Ghanaian economy.

The specific management problem is the type of national identification system, level of employee skills and training needed in information technology control application for various identification systems in the technology industry to minimize the incidence of internal and external threats, and inequitable distribution of social benefits to targeted beneficiaries. The present study sought to examine how the adaptation and implementation of a national identification system could facilitate formalization of the Ghanaian economy to accelerate her intended development and growth in all sectors.

\subsection{Research Objectives}

\subsubsection{General Objective}

The main objective of this research was to examine the effect of government's resolve to adapt and implement a national identification system on formalization of the Ghanaian economy. 


\subsubsection{Specific Objectives}

Specifically, the research sought to achieve the following objectives:

- Analyze existing laws that promote the implementation of a national identification system in Ghana.

- Examine the socio-economic benefits associated with the implementation of national identification systems in economies.

- Assess challenges related to the use of national identification systems in economies.

- Make recommendations for successful adaption and implementation of a national identification system to formalize and accelerate development and growth of various sectors of the Ghanaian and other economies.

\section{Literature Review}

Review of existing works related to the current research is presented in this section. The section commences with a brief theoretical framework and concludes with thematic discussions on empirical works essential to the present study. Themes discussed in this section include usefulness of national identification systems, and resistance to national identification systems.

\subsection{Theoretical Framework}

Drawing on security theory becomes relevant in an attempt to understand and explain key technological concepts such as national identification systems. Different seminal thinkers have proffered varied explanations on security theory. However, Baylis (as cited in Soltani \& Yusof, 2012) believes Wolfer's classical explanations on security theory are the most popular among political scientists. Wolfer (as cited in Soltani and Yusof, 2012) believes our understanding of security theory is predicated on many factors including prejudices, national characters, and preferences. He argues, in order to enhance our understanding of security theory, we need to appreciate the fact that values of a country are not under threat. Further, we need not fear about the values of the implied country.

One of the major concepts essential to the explanation on security theory is rationalism. Soltani and Yusof (2012) believe it is one of the key concepts that have enhanced individuals' perceptions on security theory while shaping the security structure of economies across the globe. The concept of rationalism hinges on positivism. This concept states facts and values are two distinct elements and that, social scientists could explain political and social phenomena in the same way as scientists add meaning to our natural world. The concept of rationalism is often explained by realism and liberalism.For instance, security issues of the Union of Soviet Socialist Republic (USSR) and the United States of America (USA) during the Cold War were analyzed based on realism(Soltani and Yusof, 2012).Dunne and Schmidt (as cited in Soltani and Yusof, 2012) indicate realism was a response to the liberal idealism of the 1920s and 1930s.Explanations on realism are further categorized into classical realism (dominant concept prior to the first decades of the 20th century), modern realism (leading concept from 1939 to 1979), and neo-realism (which gain prominence from 1979) (Soltani and Yusof, 2012). Zehfuss (as cited in Soltani and Yusof, 2012) aversproponents of rationalism advance two important arguments. That is, concepts and actors are given exogenously; and actors act in a pre-given world based on demands of instrumental reason.

Liberalism is opposed to realism in ways of providing security for a nation and its people.The liberalism concept holds the state must strive to restrain itself from acting in ways that could undermine the freedom of its people. This concept perceives relationship among peoples as progressive and subject to purposive change. Proponents of this concept argue a change in possible relations among peoples could increase trust and improve certain prevailing conditions. They admit challenges may exist. However, in spite of governments' inability to eliminate these challenges completely, steps must be taken to ameliorate their effect on the people (Griffitsas cited in Soltani and Yusof, 2012).

\subsection{Usefulness of National Identification Systems}

Khan (2018) examined the opportunities and threats associated with issuance of national identity cards. He found that though there are varied reasons for various governments' resolve to adapt and implement one national identity system or the other, there is a common factor that permeates all governments' objectives. That is, the need to create an identification system that is perfect to integrate the biometric details of each individual with a broad central database which houses or stores vast personal information. This is an ample indication of continuity in the national identification process commenced in Europe several centuries ago with improved technological features in contemporary times.

Mordini and Petrini (as cited in Khan, 2018) describe the term biometrics literally as an instrument for measuring life. Specifically, biometrics refer to the technology that is used to measure, analyze, and process digital representations of unique biological data and behavioral traits of persons, including facial patterns, finger prints, eye retinas, body odors, and hand geometry. This implies a national identification system captures vital information of a person that invariably makes him or her unique from the other. This information is accessed by governments to influence their socio-development drives for various parts of their respective economies. The foregoing affirms Khan's (2018) study which revealed the issuance of identity cards helps issuing governments to combat fraudulent acts, illegal immigration, terrorism, and to accelerate social service delivery to targeted citizens or beneficiaries.

Krupp, Rathgeb and Busch (2013) found increasing demand for biometric technologies, and constant infusion of biometrics into the lives of individuals across the globe. Further, the study revealed nations' resolve to make use of national identity cards mandatory leaves their citizens with only a choice. That is, come to terms with and holistically accept biometrics as part of their everyday lives. Krupp et al. (2013) affirm the inevitability of national identification systems in the socio-economic advancement of modern societies. 
Combet (2004)advances three major arguments to buttress the socio-economic usefulness of discussions related to national identification systems in our current dispensation. These include increasing use of technology related to national identification systems among economies across the globe; growing need for biometric data to help the police improve on crime prevention and security, and to effectively counter acts of terrorism; and the introduction of electronic chips such as electronic authentication and signature by some countries around the world. Kitiyadisai (2004) revealed following the terrorists attack on the United States of America (USA) on September 11, 2001, the need for the issuance of national identity cards has been unanimous among most developed, emerging, and developing economies across the globe. Thus, national identification systems have become necessary to help governments enhance internal and external security of their citizens; and to ensure intervention programs are effectively tailored to meet the needs of targeted beneficiaries. Rule (2005) believes the foregoing underscore various governments' decision to make the issuance of national identity cards compulsory for all citizens.

Gemal to (as cited in Khan, 2018) examined the usefulness of national identification systems in the development of the Belgian economy. The study showed Belgium is one of the first countries in the world to embark on issuance of electronic identity cards on a national scale. The aim is to ensure citizens are provided with safe and secure electronic identity card; and to have unfettered access to public and private services in the country and online. However, the House of Commons (2005) noted the fundamental objective of enacting the Identity Cards Bill in the United Kingdom (UK); and subsequent issuance of electronic identity cards is inter alia, to promote national security interest, enforce work permit laws, detect and prevent crimes, enforce immigration controls, and to improve on the efficiency and effectiveness of public services delivery. One observes while security concerns remain a dominant factor for the adaption and implementation of national identification system in the United Kingdom, improved service delivery remains the paramount objective for the issuance of same in Belgium. The variation in fundamental objectives could be attributed to the differences in the two countries' exposure to internal and external security threats. Lyon (2009) notes in Hong Kong, the need to enhance and tighten border controls informed the government's decision to introduce a sophisticated national identification system in 2003. Hong Kong's national identification system was intended to check migrants from mainland China. In Japan, the purpose of implementing the national identification system was to gather personal information of individuals such as name, date of birth, and address; and return this information to them on a card.

The European Commission (2006) named the national identification exercise in Estonia as the most successful in Europe. The national identity card issued to Estonians has many electronic applications, including verification of bills, drivers' license, digital signature, health insurance, banking details, and e-ticketing. The national identification scheme in Estonia was centered on a public-private partnership.

Islam et al. (2012) found a widespread national identification scheme in Bangladesh following its gradual inception in the 1990s. The Bangladeshi government has tied the provision of twenty-two public and private services with the ownership of national identity cards; citizens who are above 18 years must acquire a national identity card to access the foregoing services. ITU (2016) indicates the national identity card doubles as a voter identity card in Bangladesh; no eligible voter is allowed to cast his or her ballot with it. The introduction of national identification system in Bangladesh is intended, fundamentally, to ease the identification of service recipients by service providers in both private and public sectors of the economy (Election Commission as cited in Khan, 2018).

Zoleta (2018) assessed the merits and demerits associated with the implementation of national identification system in the Philippines. The study revealed until the approval of the Philippine Identification System Act (Republic Act 11055) on August 6, 2018 by President Rodrigo Duterte, the Philippines remained one of nine countries across the globe without a national identification system. The study revealed the national identity card in the Philippines can be used for all transactions, including acquisition of driver's license and passport, assess to general government services including health, job applications, tax related transactions, voter's registration and identification, bank account openings and other financial transactions, social welfare and benefits applications, application for schools, colleges, universities, and verification and clearance on criminal records, among other essential services. Zoleta's (2018) findings revealed some similarities in the primary functions of the national identification card in the Philippines and Belgium as found by Gemalto (as cited in Khan, 2018).

Zoleta (2018) noted a financial inclusion survey conducted by the Bangko Sentral in the Philippines in 2017 revealed about $34 \%$ of the adult sampled population attributed their inability to apply for a bank loan to lack of identity cards. It is believed the simple process of acquiring a national identity card in the Philippines presently would allow millions of unbanked Filipinos to open bank accounts; and access other essential banking services such as loans, investments, credit cards, and others. Implementation of the national identification system in the Philippines is expected to enhance efficiency in government related transactions; queues and transaction times are expected to be shorter than before. A recent survey conducted by SWS (as cited in Zoleta, 2018) revealed about 73\% of the sampled respondents support the implementation of the national identification system in the Philippines. The foregoing implies the level of acceptance of the national identification system among Filipinos is very high.

\subsection{Resistance to National Identification Systems}

In spite of its enormous contribution to socio-economic advancement of nations around the world, national identification systems are crept with inherent challenges that affect their outright acceptance in some jurisdictions. Zoleta (2018) revealed in recent years, websites owned by the government of the Philippines were prone to hacking. The infamous data breach in the annals of the Philippines' history known as the Comeleak was recorded in 2016 when the personal data of about fifty-five million $(55,000,000)$ voters were compromised. The recency of the security breach has raised doubts in the minds of some Filipinos on the government's ability to protect personal and confidential information 
on millions of individuals that would be collected and stored in the national identification system. However, the government has affirmed her commitment to strict implementation of the Data Privacy Act (RA10173) in the country.

Zoleta (2018) found the implementation of national identification systems could lead to violation of individuals' right to privacy. For instance, the national identification system would allow various governments an access to massive personal data of citizens and other nationals resident in their respective countries. Access to personal data could lead to government's tracking of individual and group's transactions. However, this tracking becomes problematic when it is blatantly abused or misused by custodians of millions of personal and confidential data.

The national identity card can be used for multiple functions including financial transactions. As a result, Smith (2008) and Khan (2018) believe a card lost could have dire social and financial consequences on the original bearer, that is, the individual to whom the identity card was originally issued. This presupposes the identity card holder must ensure due diligence and adequate protection of his or her card at all times to avert any financial setbacks in the near and distant future.

Khan (2018) noted in spite of the fringe benefits associated with the implementation of the national identification system, the unanticipated, unintended, and unwelcome consequences attached to its implementation require critical assessment by key stakeholders such governments of various geographical jurisdictions. The author believes all forms of national identity cards come with their attendant controversies. Kitiyadisai (2004) stated citizens of several countries around the world have raised objections to the implementation of national identification systems and eventual issuance of national identity cards to citizens. Neyland (2009) believes the citizens' objections can be attributed to factors such as skeptism in governments' ability to effectively protect and manage the multiple data of millions of citizens without security breaches.

Davies (2005) notes the growing voices of privacy and civil liberty campaigners are negatively affecting governments' ability to adapt and implement technologies that identify and track transactions of individuals. Some antiidentity card groups believe the stated merits associated with the implementation of national identification systems are exaggerated and misleading; implementation of these systems could lead to serious ethical and constitutional breaches by government officials (Milberry \& Parsons, 2013). To affirm the authenticity and validity of data stored in national identification systems, the London School of Economics (as cited in Davies et al, 2005; Khan, 2018) believes countries may have to repeat their biometric registration exercises once every five years.

Human fingers remain a major component of gathering reliable biometric data. As a result, injuries to or dirt on finger tips can affect recordability of finger prints. Scars or burns on fingers could lead to permanent loss of a fingerprint template. Petermann, Sauter and Scherz (2007) found eye diseases such as glaucoma, blindness and cataracts may lead to permanent loss of biometric data readability. The foregoing deficiencies may affect a victim's (citizen's) ability to access certain public and private services; this may have severe consequences and may limit the victim's chances of prolonged life.

ITU (2016) notes religious considerations could negatively impact on the successful implementation of national identification systems in some jurisdictions. For instance, in Bangladesh, national identification officers have challenges carrying out their functions among conservative Muslim populations. National identification officials have arduous tasks taking the biometrics of women, including iris scans and photographs in Muslim dominant areas.Kitiyadisai (2004) found the Thai government's resolve to issue a sophisticated national identity card to her citizens could create socio-economic challenges including marginalization of migrant workers; discrimination against unlettered citizens, refugees, and minority groups such as people of the Hill tribe. The author noted access to basic and essential services by the foregoing category of people in Thailand would be a challenge owing to the introduction of an electronic identity card which captures sensitive data of all registrants.

\section{Research Methodology}

The systematic exploratory technique, an example of the mixed methods approach to scientific inquiry, was adapted for this research. That is, the research was conducted with strong qualitative leanings though elements of both qualitative and quantitative methods were present (Ashley, Takyi \& Obeng, 2016; Creswell, 2009). Secondary sources were identified as the most reliable means of gathering relevant data for the present study. Thus, data required for the conduct of this research were obtained mainly from secondary sources. These included text books, peer-reviewed articles in journals, news paper publications, and the Internet, among other sources.

\section{Research Findings and Discussions}

\subsection{National Identification Systems in model Economies}

Findings from the present study revealed adaption and implementation of national identification systems have yielded varied socio-economic results in some emerging and developing economies such as India, Peru, Thailand and Pakistan. For instance, in India, implementation of the Aadhaar system helps in the generation of unique identification numbers for citizens (about 1.36 billion population); and ensures benefits and subsidies reach the targeted population. The efficiency of the Aadhaar system helped the Indian government to reduce financial waste; increase returns on social investments; and save to pay for the cost of the system within a short period of time. India remains the economy with the largest biometric-based identity scheme in the world (Jacobsen, 2012).

An effective national identification system continually helps the Peruvian Government to send relief items, with relative ease, to affected victims in times of natural disasters. Similarly, the Thai Government, through its strong national 
identification system, has succeeded in providing universal health coverage for the population. The identification system has helped to improve on the level of health service delivery in Peru.

The effective use of biometric technology in Pakistan helps the government to transfer financial assistance to targeted beneficiaries such as women. Beneficiaries are able to make informed and independent decisions on mode of expenditure on funds received from the government. Prior to the issuance of the national identity card, some businesses in the Philippines only accepted and honored senior citizen identity cards. That is, cards issued to individuals who are sixty years and above. However, the Senior Citizens Law in the Philippines is clear on the presentation of any governmentissued identity card by seniors to receive discounts. This prevented seniors without the senior citizen identity cards from enjoying discounts on goods and services in the country. The national identity card is expected to ease the challenges on discounts received by senior citizens when they patronize goods and services in the country. The Philippines identity card (PhilID) is expected to have enhanced security features as in banknotes, passports, and other governments' identity cards across the globe.

Countries such as South Korea, China, Singapore, Spain, Italy, and France have taken steps to issue national identity cards to their citizens (Zoleta, 2018). Some advanced countries considering use of national identification systems include the United Statesof America(USA), Australiaand Canada. Here, the consideration is remote; and this may be attributed to the de facto national identification in the issuance of a social security card in some of these countries; and control and privacy issues raised by anti-identity card groups in these countries. Another advanced economy considering the use of a national identification system is the United Kingdom. The consideration in the United Kingdom is immediate in spite of concerns raised by anti-identity card groups (Fussell, 2004; Neyland, 2009).

\subsection{National Identification Authority Initiatives in Ghana}

Findings from the study revealed several enactments have been passed by the Parliament of Ghana and received Presidential assents to ensure the adaption and implementation of a national identification system in the country. These include the National Identification Authority Act of 2006 (Act 707), National Identity Register Act of 2008 (Act 750), National Identity Regulations of 2012 (L. 2111), and National Identity Register (Amendment) Act of 2017 (Act 950). These enactments are not mutually exclusive, they are interrelated; they are intended to enhance the object of national identification in Ghana. The foregoing enactments were passed and assented to accelerate NIA's functions, operations and services to the general public in relation to the issuance of national identity cards with international features, standards, and quality.

World Population Review (2019) estimates Ghana's current population at 30.04 million (specifically, 30,037,370). In terms of population size, Ghana is ranked $48^{\text {th }}$ out of 230 countries and territories in the world. Ghana is ranked next to Mozambique who has an estimated national population size of 31.33 million and ranked $47^{\text {th }}$ in the world.The National Identification Authority in Ghana has an arduous task of registering and issuing identity cards to over 15 million eligible Ghanaian citizens.In September 2006, the French solutions provider, Safran Morpho, formerly called Sagem Securite, was contracted by the Ghana Government to ensure the registration and issuance of identity cards to all Ghanaians and foreign nationals resident in the country. The maiden national identification exercise was carried out in the then ten regions as follows:Central region - July 2008; Western region - August 2008; Eastern region - October 2008; Volta region - April 2009; Greater Accra region - November 2009; Ashanti region - April 2010; BrongAhafo region - March 2012; Northern, Upper West and Upper East regions - August 2013.

At the end of the five-year exercise, the following brief statistics were recorded: More than 15 million demographic and biometric data were collected from Ghanaians aged 6 and above; only 9,120,476 out of the over 15 million data were entered into the database; only 4,565,017 data out of the 9,120,476 entered into the database were processed and completed with personal identification numbers (PINs) generated. The processed and completed data represented about $50.05 \%$ of the data entered; about 2.72 million GhanaCards were generated and printed for the Greater Accraregion and part of the Ashanti region. Out of this number, only 915,000 Ghana Cards were distributed in the Greater Accra region; and about $49.95 \%$ of data entered into the identification system were rejected completely, or left hanging in some error queue. From the above, there is no gain-saying the entire national identification process was fraught with challenges and very limited success. This culminated in the need for renewed national spirit and effort to carry out the mass registration exercise to its logical conclusion. The renewed nationalism is exemplified in the commitment of leadership of the present administration in the country. Under the current President, Nana Akufo-Addo, funds have been sourced for the NIA to ensure mass registration of all people, both citizens and residents, in the country. The mass registration exercise is expected to be rolled-out successfully throughout the country. The role of authentic and reliable personal data through an effective national identification system in the socio-economic development of developing economies such as Ghana cannot be over-emphasized.

The reconstituted National Identification Authority announced its plans to start a nationwide registration exercise which would ensure the biographic and biometric data of all Ghanaians are duly captured; and eventually issued with national identity cards. As earlier announced by Prof. Ken Agyemang Attefuah, the Executive Director of the NIA, the countrywide exercise is expected to be rolled out in the Greater Accra region(the nation's capital city) with special attention to banks, schools, security agencies, and the general population. The exercise is expected to be continued in the Central, Western and BrongAhafo regions; and later extended to the remaining regions in Ghana. Like the issuance of passports, Ghanaians resident abroad would have the opportunity to own a copy of the national identification card at a price. The new national identity card would be embedded with 14 international security features. This would enhance its quality, durability and acceptability within the West African sub region and beyond. 


\subsection{Forms of National Identification Systems}

Findings from the research showed generally, there are three categories of national identification systems. These include paper-based, readable plastic card, and smart integrated systems. The paper-based system involves extensive use of manual documentation with minimal reliance on computer and related technologies; the eventual card issued to holders may be in a paper form. The cost of maintaining this system is low. However, it is highly prone to data forgery. The readable plastic card system is an improvement over the paper-based system. Because it has a plastic component, it is more durable than the paper-based card; it has a relatively high cost; and susceptible to forgery.

The smart integrated system is the one that is in vogue; it is the system with broader functionality and high maintenance cost. However, the incidence of theft associated with the smart integrated system is relatively low. Based on its socio-economic effectiveness, usefulness and benefits, we recommend the smart integrated system for the National Identification Authority (NIA). When the Thai government was saddled with two major challenges, that is, social unrest in the southern part and increasing acts of terrorism in the country, she adapted and implemented the Smart Integrated System as a counter terrorism tool (Kitiyadisai, 2004).

\subsection{The Need for a National Identification System}

A well-established national identification system would help distinguish law-abiding citizens and non-citizens from terrorists and other criminals. It would help combat terrorism and related crimes; tackle the issue of immigration and work permits for immigrants; strategically combat identity theft; minimize tax evasion and number of welfare beneficiaries; provide proof of age; and provide relevant information in times of medical emergency, among others.

\subsection{Benefits of National Identification System to the Ghanaian Economy}

The research outcomes revealed the government of Ghana's decision to adapt, install and implement a national identification system comes with a number of socio-economic benefits to the country. Notable among these include ensuring integration of systems across government ministries, departments, and agencies to help avoid duplication of data and programs; improving health coverage and overall health service delivery; ensuring government social intervention programs such as the Livelihood Empowerment Against Poverty (LEAP) benefits go directly to targeted beneficiaries; ensuringan improvement in the dispatch of relief items by the National Disaster Management Organization (NADMO) to flood and flood-related victims; making sure government subsidies are provided for targeted recipients; and improving customer identification system for rapid loan processing and approval by various financial institutions.

Further, it would improve the country's population estimates for essential national planning and development; enablevoters to exercise their voting franchise with relative ease since the Electoral Commission can rely heavily on the National Identification Authority's authentic data for direct registration and voting purposes; fairly estimate the number of migrants in the country; ensure efficient allocation and utilization of the nation's limited natural, financial and human capital resources; enhance the accuracy and reliability of data churned out by the Ghana Statistical Service and other government agencies for present and future policy formulation and implementation; harmonize government structures and systems for effective co-ordination and governing process; and ensure rapid provision of key infrastructural facilities leading to economic development and growth.

Also, the scheme is expected to facilitate the analysis of teething and lasting problems and proffering of appropriate solutions; provide a national identity card that would serve as a de facto social security card as it pertains in other jurisdictions; increase the number of citizens with identification cards; provide efficient and effective services at the national level; and assist the government to realize the United Nations Sustainable Development Goals (SDGs), especially SDG 16.9, which states inter alia: "By 2030, [each country shall] provide legal identity for all, including birth registration."

Finally, the government is expected to implement a system that provides unique identification that is biometrically secure and aids in the provision of wide range of useful services for the underserved consumers in the areas of education, health, and financial services. These services would be on an integrated platform that brings all citizens together in a seamless manner; a system that serves as a substitute for a passport in domestic airline travels; install an effective system that would lead to seamless interconnectivity of various management systems for strong electronic commerce (e-commerce) and electronic governance (e-governance) in the Ghanaian economy.

\subsection{Challenges of National Identification System to the Ghanaian Economy}

The success story of the national identification system is likely to be marred by a number of challenges, including limited funding and untimely release of funds for its day-to-day operations, projects and investments. For instance, in 2007, a French Government budgetary allocation of GH\$30 million for the national identification exercise was not released by the Ghanaian Government to the National Identification Authority. Similarly, in 2014, the NIA requested for GH $\$ 3,076,467.60$ to settle outstanding bills of $\mathrm{GH} \$ 4,288,737.46$ and to meet other financial needs. However, only GH\$760,000, representing about 5.8\% of the total request was released to the National Identification Authority. Findings from the research revealed the release of funds to the National Identification Authority for capital expenditure and investment in prior periods was a challenge.

Akin to the above may be difficulties in identifying sustain able sources of funding for the national identification exercise in the medium- and long-term. There may be difficulty in ensuring the estimated over 15 million Ghanaians are duly registered and presented with national identity cards within a limited time frame as earlier envisaged bythe President, Nana Akufo-Addo. Indeed, issuance of instant digital or electronic cards to all citizens throughout the country within a three-month period may be very challenging, if the requisite logistics are not adequately provided and deployed to designated areas on time. 
The success of the registration process may be marred by inability to ensure effective deduplication and quality assurance processes to avoid rejection of valuable data. The foregoing may be a major setback to the NIA. Harmonisation and alignment of multiple forms of identification programmes funded by different agencies may be a hurdle for the NIA. Another challenge may bethe likelihood to precede system installation and staff training with citizens' data collection. In the past, system installation and staff training were completed three yearsafter data have been collected from the field.

Security breaches by some staff members and hackers may be a major challenge to the NIA. That is, protection of citizens' right, privacy and sensitive information may be threatened by system intruders - unauthorised internal and external users of citizens' information. The implementation process may be affected by the tendency to collect poor data from the field resulting in waste of limited financial resources. For instance, it turned out from the previous exercise that parts of the data collected from the then Northern region for the identification system were rejected. Another impeding factor is the fear of abuse of power by government functionaries. Unfettered access to citizens' information may allow some political officials to exact vengeance on other citizens; or subject some innocent citizens to constant harassment, sabotage or victimization.

\section{Recommendations}

In view of the challenges likely to retard the progress of the National Identification Authority and ostensibly negate the overall national agenda of providing a uniform identity card for all citizens and non-citizens, the following recommendations are proffered.

- $\quad$ Staff of the NIA should be adequately resourced in terms of training and equipment to facilitate harmonization and integration of all public data into one data warehouse.

- Functions of the National Identification Authority must be effectively prioritized. For instance, data collection must not precede installation of data input system as witnessed in prior national identification exercises.

- The present national identification system must effectively capture basic contact information such as electronic mail (e-mail) addresses and telephone numbers of registrants to facilitate their contact in future, should the need arise. The absence of this basic information in the previous national identification system affected, severely, the effective distribution of completed national identity cards to their rightful owners; millions of completed identity cards are locked up in the warehouse of the National Identification Authority because officials have difficulties contacting the owners.

- The NIA could use mobile registration vans to help reach out to individuals in remote parts of the country.An individual's fingerprints can be used as a unique identification in proxy for a missing or misplaced identity card.

- The new national identity card must be friendly to the visually-impaired; it must include a tactile feature to ease its usage by the visually-impaired.

- $\quad$ The NIA must ensure higher stakeholder and user agencies involvement in its quest to establish and maintain very reliable national identification system; and national identity register (NIR). Some stakeholders and user agencies include the Births and Deaths Registry, National Communications Authority (NCA), Chamber of Telecoms, Ghana Immigration Service (GIS), Passport Office, Bank of Ghana, commercial banks and other key financial institutions, Controller and Accountant General's Department, Social Security and National Insurance Trust (SSNIT), National Health Insurance Authority (NHIA), the Police, National Security, National Pensions Regulatory Authority (NPRA), Driver Vehicle Licensing Authority (DVLA), Ghana Revenue Authority (GRA), National Population Authority (NPA), and others.

- $\quad$ The NIA must ensure economic hiring and management of staff.That is, the NIA must avoid hiring excess labour; and eliminate ghost names from the payroll to cut down its cost of operations, using modern identity management techniques.

- $\quad$ Under the National Identity Register Regulations of 2012, L. 2111, use of the GhanaCard is compulsory in all transactions requiring identification in Ghana. Therefore, it behoves the National Identification Authority to harness the requisite financial, technological, material, and human resources to ensure a national identity card is issued to all citizens within the stipulated time.

- The Board and Management of the National Identification Authority must ensure value-for-money by adapting the right system for the registration process; they must ensure routine checks and maintenance of the system for prolonged lifespan and continuous operational efficiency. The NIA must "cure" the national malaise of poor maintenance culture by taking proactive steps to periodically carryout maintenance on its equipment. The NIA must set the pace for renewed and good national maintenance cultureforother government departments and agencies to follow.

- Protection of citizens' and non-citizens' sensitive information must be of utmost concern to the NIA; sophisticated technology that could protect registrants' data against hacking should be acquired and used by the NIA.Also, it must ensure strict adherence to and implementation of the content of the Data Protection Act of 2012, Act 843 to assure the privacy of all registrants.

- The NIA could employ sophisticated technological equipment or software such as blockchain, distributed hosting and authentication protocols to mitigate risks that may be inherent in its identification system. Also, services of technology experts from economies such as India with effective national identification system could be engaged, periodically, to enhance the technological expertise and capacity of Ghanaians who would be incharge of our national identification system. 
- $\quad$ Cost to be incurred or already incurred in acquiring equipment for the national identification system must be economically meaningful to enable it pass post-administration audit and litmus test. Stated differently, cost of the equipment should not eventually result in act of willfully or inadvertently causing financial loss to the state.

- $\quad$ Limited funding and delays in the release of funds as witnessed under the previous management of the NIA should not be encouraged under the present administration; such financial bottlenecks could prove fatal to the success of the overall exercise. Budgetary allocations must be released on time; adequate funding for nationwide coverage must be provided by the government. It is hoped funds already sourced for the mass registration would meet the total cost of the entire exercise across the country. It is worth-emphasizing that the NIA could take proactive steps to be a revenue-deriving body rather than cost-incurring institution.

- The national identification system must be evaluated and assessed routinely for possible replacement in order to be constantly abreast of time and achieve the requisite statutory mandate. Current technologies of Ghana's NIA must be compared with technologies employed by similar emerging or advanced economies for reliability, efficiency and effectiveness. In addition, the system must meet standards and certification of the International Standards Organisation (ISO), other relevant standard-setting bodies and credit rating agencies across the globe.

- In line with statutory requirements, the National Identification Authority must submit annual report to Parliament through its sector ministry. The report must outline the achievements, challenges; and medium-and long-term plans of the National Identification Authority.

\section{References}

i. Akrofi-Larbi, R. (2015). Challenges of national identification in Ghana.Information and Knowledge Management, 5(4), 42-46.

ii. Al-Khouri, A. M. (n.d.). Facing the challenge of enrolment in national ID schemes.Emirates IdentityAuthority, 1328.

iii. Ashley, E. M., Takyi, H., \& Obeng, B. (2016). Research Methods: Quantitative and Qualitative Approaches to Scientific Inquiry. Accra: The Advent Press.

iv. Clarke, R. (1994). Human identification in information systems: Management challenges and public policy issues. Information Technology \& People, 7(4), 6-37.

v. Combet, E. (2004). The key to ID cards: "Identity card usages," not "identity usages." Oxford International Institute, 3(1).

vi. Creswell, J. W. (2009). Research Design: Qualitative, Quantitative, and Mixed Methods Approaches (3rd ed.). Thousand Oaks, CA: Sage Publications.

vii. Davies, S. (n.d.). Identity cards: Strategy, implementation \&challenges. Privacy International.

viii. Davies, S. (2005). The complete ID premier. Index on Censorship, 34, 38-43.

ix. Davies, S., Hosein, I., \& Whitley, E. A. (2005). An assessment of the UK identity cards bills and its implications. London: LSE Research Online.

x. Digital Impact Alliance.(2017). Taking pragmatic steps to advance national ID efforts for development. Retrieved from https:/ / digitalimpactalliance.org/ taking-pragmatic-steps-advance-national-id-efforts-development/

xi. Dotse, H. (2017).National ID; data security, privacy and our civil liberties! Retrieved from http:/ / starrfmonline.com/ 2017/ 07/ 16/ national-id-data-security-privacy-and-our-civil-liberties/

xii. European Commission. (2006). E-ID in Estonia. Retrieved from http:/ / www.epractice.eu/ files/ documents/ cases/ 191-1170255573.pdf

xiii. Fussell, G. (2004). Genocide and group classification on national ID cards. In C. Watner and W. McElory (Eds.). National identification systems: Essays in opposition. (pp. 55-69). Jefferson: McFarland \& Company, Inc.

xiv. Ghanaweb.com. (2007).National identification system and its importance. Retrieved from https:/ / www.ghanaweb.com/ GhanaHomePage/ NewsArchive/ National-Identification-System-and-it-s importance-121391.

xv. Ghanaweb.com. (2017).Features of Ghana Card. Retrieved from https:/ / www.ghanaweb.com/ GhanaHomePage/ NewsArchive/ Only-the-GhanaCard-will-confirm-your-identityas-Ghanaian-Prof-Ken-Attafuah-581710.

xvi. Hornung, G., \& Robnagel, A. (2010). An ID card for the internet-The new German card with "electronic proof of identity." Computer, Law \& Security Review, 26(2), 151-157.

xvii. House of Commons. (2005). Identity cards bill. Retrieved from http:/ / www.publications.parliament.uk/ pa/ cm200506/ cmbills/ 009/ 2006009.pdf

xviii. Islam, M. R., Baniamin, H. M., \& Rajib, M. S. U. (2012). Institutional mechanism of national identification card: Bangladesh experience. Public Policy and Administration Research, 2(2), 1-13.

xix. ITU. (2016). Review of national identity programs. Geneva: International telecommunication Union (ITU). Retrieved from https:/ / www.google.com/ search?

xx. Jacobsen, E. K. U. (2012). Unique identification: Inclusion and surveillance in the Indian biometric assemblage. Security Dialogue, 43(5), 457-474.

xxi. Jamaican Parliament. (2017). The National Identification and Registration Act (Act of 2017). Retrieved from https:/ / japarliament.gov.jm/ attachments/ article/ 339/ The\%20National\%20Identification\%20and\%20Registrat ion\%20Act,\%202017.pdf

xxii. Khan, A. R. (2018). National identity card: Opportunities and threats. Journal of Asian Research, 2(2), 78 
xxiii. Kitiyadisai, K. (2004). Smart ID card in Thailand from a Buddhist perspective. MANUSYA: Journal of Humanities (Special issue), 8, 37-45.

xxiv. Krupp, A., Rathgeb, C., \& Busch, C. (2013). Social acceptance of biometric technologies in Germany: A Survey. In A. Bromme, \& C. Busch (Eds.). Proceeding of 2013 International Conference of the BIOSIG Special Interest Group (BIOSIG) (pp. 193-200).

xxv. Kwiringira, S. (2017).Integration of services withthe national identification system, Uganda's case. National Identification and Registration Authority.

xxvi. Lyon, D. (2009). Identifying citizens: ID cards as surveillance. Cambridge: Polity Press.

xxvii. Michael, K, \& Michael, M. G. (2006). Historical lessons on ID technology and the consequences of an unchecked trajectory. Prometheus, 24(4), 365-377.

xxviii. Milberry, K., \& Parsons, C. (2013). A national ID card by stealth? The BC services card privacy risks, opportunities and alternatives. Vancouver: BC Civil Liberties Association.

xxix. National Identification Authority.(2014). Ghana NIA's legal mandate. National Identification Authority.

xxx. Neyland, D. (2009). Who's who? The biometric future and the politics of identity. European Journal of Criminology, 6(2), 135-155.

xxxi. NIA. (n.d.). L2111 National Identity Register Act 2008 (Act 750)-National Identification Authority. Retrieved from https:/ / www.nia.gov.gh.

xxxii. NIA. (n.d.). Our history-NIA-National Identification Authority. Retrieved from https:/ / www.nia.gov.gh.

xxxiii. NIA. (n.d.). Privacy policy-NIA-National Identification Authority. Retrieved from https:/ / www.nia.gov.gh.

xxxiv. Petermann, T., Sauter, A., \& Scherz, C. (2006). Biometrics and the borders-The challenges of a political technology. International Review of Law, Computers and Technology, 20(1\&2), 149-166

xxxv. Refworld. (2006). Ghana: Act No. 707 of 2006, National Identification Authority Act. Retrieved from https:/ / www.refworld.org/ docid/ 548edfa94.html

xxxvi. Refworld. (2008). Ghana: Act No. 750 of 2008, National Identity Register Act. Retrieved from https:/ / www.refworld.org/ cgi-bin/ texis/ vtx/ rwmain?docid $=548 e e 10 b 4$

xxxvii. Rule, J. B. (2005). Time to ask questions about the paths opened by ID cards. Oxford: Oxford Internet Institute.

xxxviii. Smith, A. D. (2008). The benefits and risks of national identification programme. Retrieved from http:/ / www.emeraldgrouppublishing.com/ learning/ mamagement thinking/ articles/ pdf/

xxxix. Soltani, F., \& Yusof, M. A. (2012). Concept of security in the theoretical approaches. Research Journal of International Studies, 1. ISSN: 1453-212X

xl. Sullivan, C. L. (2011). Digital identity: The emergent legal concept. Adelaide: University of Adelaide Press.

xli. The World Bank Group.(2017). Identification for development (ID4D). Retrieved from http:/ / www.worldbank.org/ en/ programs/ id4d\#1.

xlii. Whitley, E. A. \& Hosein, G. (2010). Global identity policies and technology: Do we understand the question? Global Policy, 1(2), 209-215.

xliii. World Population Review. (2019). 2019 world population by country. Retrieved from http:/ / worldpopulationreview.com/

xliv. Zoleta, V. (2018). National ID system in the Philippines: The good and the bad. Retrieved from www.moneymax.ph 